Vol. 10(17), pp. 2481-2488, 10 September, 2015

DOI: $10.5897 /$ ERR2015.2405

Article Number: 827F3C655317

ISSN 1990-3839

Educational Research and Reviews

Copyright (c) 2015

Author(s) retain the copyright of this article

http://www.academicjournals.org/ERR

\title{
The implications of Feyerabend's epistemological approach for educational research methods
}

\author{
Elham Shirvani Ghadikolaei ${ }^{1 *}$ and Seyed Mahdi Sajjadi ${ }^{2}$ \\ ${ }^{1}$ Allameh Tabataba'i University, Iran. \\ ${ }^{2}$ Tarbiat Modares University, Iran.
}

Received 15 July, 2015; Accepted 28 August, 2015

\begin{abstract}
Epistemology is defined as theory of knowledge and the ways of achieving it. Epistemology is research questions of the possibility of knowledge and the riddle of knowledge. Epistemology and methodology despite being interconnected are inseparable and are not reducible from each other. In addition, their relationship is direct, meaning that ontology logically precedes epistemology and epistemology proceeds methodology, logically. In other words, it has very close relations with epistemology; there are three types of methodology: proof, interpretive and critical. In this paper, we seek to examine the perspective of Feyerabend's epistemology and its implications in research of methodology. We will first review and analyze the paradigms of research methodology and then, the description of Feyerabend's epistemology, and finally, assess the implications of methodological approach to research in education from Feyerabend's point of view.
\end{abstract}

Key words: Epistemology, methodology, educationalresearch implications, Feyerabend.

\section{INTRODUCTION}

One of the main concerns of Feyerabend in his second study of epistemology is how to deal with rational science. In fact in this article, we take a look at the rationality of science from Feyerabend's perspective. We also explain Feyerabend's features of methodological approach to Educational research. Most experts, in fact, believe that Feyerabend, in his first period of ideas, in respect to the theory of scientific rationality or reasonableness, has a convincing and plausible view. But in the second period he only reviews sheer failings of practical science and rejection of any reasonableness in science in the role of an anarchist philosopher. He becomes completely relativistic and has a postmodern position towards science. But some experts believe that
Feyerabend has accepted scientific rationality and does not exclude scientific rationality; rather, he has a new approach to the rationality of knowledge. They also believe that Feyerabend believes that we do not just have one unparalleled and unique rationality, harmonic to ordinary and standard common sense. Hence we can say that the explanation of the scientific plausibility of Feyerabend's view largely explains his approach to epistemology as well. The purpose of writing this article, in fact, is to explain Feyerabend's epistemological perspective and review his reasoning in methodological implications of education research. This article seeks to answer the fundamental question that are implications of Feyerabend's epistemological perspective for research in

*Corresponding author. E-mail: shirvanel@gamil.com.

Authors agree that this article remain permanently open access under the terms of the Creative Commons Attribution License 4.0 International License 
education and what kind of critics can be used for said implications. In this article we will explains the epistemological perspective of Feyerabend first accompanied by discussion of his epistemological analysis of the basic concepts in theory. And then to deduce the educational implications of Feyerabend's view that action on Educational Research. At the end we will discuss Feyerabend's view of the implications for Educational Research Methodology.

\section{PARADIGMS OF METHODOLOGY}

Paradigms of methodology divide into three sections that in no way can be added up together or be separated:

\section{Positivistic methodology}

The root of this positivism goes back to ancient Greek, but in its prominent form, in the humanities' science, was first considered by Comte (1797-1857) in the $19^{\text {th }}$ century. August Conte believed that one can establish a new social science by proposing that social sciences, based on proof, as is common in the humanities. In fact, he claimed that social phenomena can be studied like physical phenomena, as an experiment (Waraki, 2007).

Positivists believe that there is only one scientific reasoning, and that is logic of natural science. Accordingly, the difference between the natural sciences and the humanities, relates to its issues (Iman, 2007).In the field of educational research, a positivist approach believes that educational research, as in natural sciences research, must seek to explain and achieve the causal mechanisms of the educational phenomena. Then, with application of the knowledge gained, exercise appropriate changes in them.

Positivism considers reality as something that can be understood through the senses and see reality out of human existence and independence, rather see it completely objective. Positivism explains the researcher of phenomena as regular and visible, in separation of scientific knowledge from unscientific, insists on methods of the natural sciences as tools of scientific knowledge and considers another human experience and knowledge outside the field of science. It considers methods based on religion and myth, as unscientific methods and whatever that is focused in scientific knowledge is based on observations, from the perspective of positivism, is the goal of scientific research and discovery of a phenomenon. Scientific research is a tool to study identify social realities and ultimately prediction and control of reality.

\section{Interpretation methodology}

Interpretive flourished with the late nineteenth century as it approached a deadlock with empiricism. Dilthey (2003) must be considered the architect of this theory, who according to Freud, was theoretician of Muslim human Sciences and will remain (Waraki, 2007).Interpretive methodology in the humanities is somehow relevant to the theories of the German sociologist Max Weber (19201864) who believed in distinction between the humanities and the natural sciences and believes in social interaction in humanities. While emphasizing the meaningful social interaction, with the tendency to purpose (goal), tends to the concept of understanding. This is to see people reflection in meaning creation and reasons and motivations (Iman, 2007). Interpretive Methodology, in a way, wants to study that ordinary people how to spend their daily lives and how they tend to their daily work? To obtain answers to these questions, action is taken to design research based on qualitative approach that is specific to Humanities. The basic principles of qualitative approach, which is required interpretation of the central concepts, is based on communication, interpretation, understanding and what everyday life (Ibid). Interpretive methodology, criticizing the positivism approach, which seeks to explain the causal relationship, considers positivism approach a natural science approach. In human sciences, unlike that of positivism approach, the researcher simply doesn't deal with matter and cause and effect and others, but rather deals with concepts such as dynamics, evolution of motivation, purpose, reason, and in particular the concepts of value and meaning (Zarghami, 2011).

In the interpretation of reality is not something external and is not independent from the researcher and the social world is not predetermined fact that researchers just discover. It is rather reality of life and experience of the investigator or people who are linked and in way facts of each individual depends on experiences in life and people's point of view. The interpretive approach, therefore, is a human oriented approach and pays much attention to the human experience. Accordingly interpretation orientated believes that science as proof, cannot explain the foundation of life for individuals. What is important is that understanding people's everyday life that is guided by common sense (Iman, 2007).

Interpretation methodology is the theoretical basis of qualitative research in the field of educational research. It can be said that qualitative research versus quantitative research can be very small and is somehow lesser welcomed by educational researchers.

\section{Critical methodology}

Within the paradigm of criticism, research objective, is change the status quo for social equality and more social freedom. In this path there are two basic steps necessary: first, recognition, review and sectional awareness about the systematic domination and oppression, which are the main obstacle to equality and freedom of 
human beings and second, taking action to eliminate them (Zarghami, 2011). In this regard, the basic approach of critical methodology is to review ideologies and social structures that inhibit social freedom and equality. From this basic critical methodology, approaches such as dialectical materialism, class analysis, manufacturing, integration, and the feminism are seen (Iman, 2007).

Critical Methodology asserts many layers of reality, that behind the apparent layer, deep structures or invisible mechanisms exist. Discovering these structures or mechanisms through direct and deep questions, it is possible for a valid theory of the universe and reestablishment of the historical approach. On the path to discovery of reality, subjective meaning of actors and objective relationships (material) that form the basis of social relations and are focused in interpretation and positive methodologies, established based-identification and analyze current events in critical approach.

\section{FEYERABEND'S EPISTEMOLOGY}

By Feyerabend (1993)'s account of rationality and epistemology, freedom has a special place the most important Feyerabend's idea is in explanation of accepted knowledge. He believes that a free society, a society in which all traditions, equal rights, equal access to education, and other strong opportunities are provided. If traditions can only be an advantage in terms of other traditions; then selecting a tradition as the foundation of a free society, is a voluntary action that can only be resorted by justified force (Feyerabend, 1993).

In fact, James Kidd (2015) believes that Feyerabend:

"The second rationale concerns Feyerabend's concern with the epistemic integrity of science, especially given its authoritative status in late modern societies. If this sounds odd, given his status as the worst enemy of science' and his disturbing calls for the separation of science and the state, then I urge caution. In fact, a defense of the integrity of science. Feyerabend made those defenses to critically expose failures by members of the scientific establishment to honor the epistemic values and ideals that are constitutive of the authoritative status of science. If so, then Feyerabend should emerge as more conservative and less radical than man might suppose" (James Kidd, 2015).

Feyerabend in his book "Against Method" says, "I repeat that this free occupation is not just a fact of history of science, but it is reasonable and absolutely essential for the growth of knowledge. In particular, it can be shown that for every "basic "or "rational" rule, there are always conditions just when that rule is recommended, not only ignore the rule, but also accept the opposite. For example, when there are appropriate conditions for the production and interpretation and defense of local hypotheses conflict with the generally accepted results and researcher, or other hypotheses that are minimal in content compared to experimental hypotheses or hypotheses that are inconsistent (Fayerabend, 1996).

Feyerabend's approach to saddened freedom from "Stewart Mill" and the most important dimension that Feyerabend targets in critique of rationality and limiting science is the dimension of training and education. Feyerabend in the analysis of issue of freedom, points to two problems in common education and training, first simplify the environment that the scientist works in by simplifying the main factors by the scientist, him/herself. It may finally have to be said that the history of science is precisely the phenomenon and the results that can be derived from them, it is not formed by them (Feyerabend, 1996). The history of science is complex and full of errors. In Feyerabend's view, the history of the formation of knowledge hasn't been like this which we see in books or taught in schools and universities, rather it is delivered to students in the form of naked phenomenon. Feyerabend's purpose of this review is that why the new learners aren't permitted to make mistakes and experience deviations in science and thought to creativity. This method is an authoritarian method and prevents real freedom of the individual and in the same way Feyerabend in his book, "Against Method" says:

"Scientific education as we know it today has precisely this aim. Its implies 'science' by simplifying its participants: first, a domain of research is defined. The domain is separated from the rest of history (physics, for example, is separated from metaphysics and from theology) and given 'logic' of its own. A thorough training in such 'logic' then conditions those working in the domain; it makes their actions more uniform and it freezes large parts of the historical process as well. Stable 'facts' arise and persevere despite the vicissitudes of history. An essential part of the training that makes such facts appears consists in the attempt to inhibit intuitions that might lead to a blurring of boundaries "(Feyerabend, 1993).

Feyerabend identifies this kind of training and scientific research methods and determine the scope of the evidence, as limiting individual freedoms. If we interpret Feyerabend's anarchist methodology politically, Feyerabend's considerations for freedom and benefit of society in seek of real research of democracy to the sense of the word.

Feyerabend understands the real democracy as one that "basically, any assembly of free people should respect their own members' false beliefs and provide institutional support". "A society based on rationalism is not a completely free society. A person in this society has to play the role of an intellectual". On the other hand, philosophy of pragmatism leads an open exchange. Fans in an open exchange accept the tradition that is uncertain 
in the beginning and expands during the exchange. This person respects open exchange of the opponent, whether he is an individual or fully cultural, while respecting the intellectual exchange of the opponent within the intellectual framework. Open exchange has no tools, it may invent it, but has no logic even though, and it may emerge during the new forms of logic. A free society is a society in which all traditions have equal rights (Feyerabend, 1996).

In fact in Feyerabend's view:

"Pursuing science is a choice we make to live a certain way, to live in a certain kind of world, to pursue prediction and control ratherrthan rest on authority and tradition "(Brown, 2014)

Freedom in Feyerabend's view is defined in the rational community in such way that a person is creativity killer and accepts the free intellectual society which has been guided. This freedom, as far as Feyerabend is concerned, has no originality and somehow is another reading of tyranny that in flow of time has been stricken with this tyranny and on the other hand plays a major role in the stability of the dictatorship science.

"In a free society all traditions should have equal rights in a liberal state. There is no reason why science should have special status in society in comparison to other traditions. Rather, in a free society all traditions should have equal backing by the state"(HoyningenHuene, 1994).

\section{RICHNESS OF EXISTENCE}

Feyerabend, in the opening of his book, "Against Method" says:

"History generally, and the history of revolution in particular, is always richer in content, more varied, more many-sided, more lively and subtle than even' the best historian and the best methodologist can imagine. History is full of 'accidents and conjunctures and curious juxtapositions of events' and it demonstrates to us the 'complexity of human change and the unpredictable character of the ultimate consequences of any given act or decision of men'. Are we really to believe that the naive and simple-minded rules which methodologists take as their guide is capable of accounting for such a 'maze of interactions? And is it not clear that successful participation in a process of this kind is possible only for a ruthless opportunist who is not tied to any particular philosophy and who adopts whatever procedure seems to fit the occasion" (Feyerabend, 1993)?

Hoyningen-Huene (2000) believed that:

"The target of Fyrabaned's attack in against method was a specific epistemological (self) understanding of the sciences, one that reduces special quality of scientific knowledge to the strict application mother natural science from the very begging and its essentials can be traced back to the Greeks of antiquity. Strict rules to achieve a certain target are called "methods". In his book, Feyrebend questioned the existence of such strictly binding scientific methods. Thus the title against method and its subtitle that contains the concept of anarchism: anarchism as antithesis to the unconditional reign of one or more methods" (Hoyningen-Huene, 2000).

\section{FEYERABEND'S VIEW OF EDUCATIONAL RESEARCH, METHODOLOGICAL IMPLICATIONS}

Feyerabend's implications for approach for field of education and educational research methodologies, divide to two levels of general and specific implications. General implications are concerned for criticism of the lack of training and scientific independence, where at the end are trained as researchers or learners. This area has the acceptance of interest to its intellectual meaning and implications of the approach and methodology and defects and shortcomings in Feyerabend's view, and consequently how and certainty from the perspective of educational research in Faybrand's view.

If we consider the purpose of good education for a good life or the purpose of a good life our goal in education, undoubtedly, being single-method in education and imposing any method would be contrary to the real good life and good training. In this context, Feyerabend in the introduction his book says:

"My main motive in writing the book was humanitarian, not intellectual. I wanted to support people, not to 'advance knowledge" (Feyerabend, 1993).

People around the world have developed living in unacceptable risks and circumstances. Stories they tell and activities they par take, has developed their lives, has maintained them, and it has given them meaning. "The advancement of knowledge and civilization", as the imposition of methods and Western values, to all corners of the Earth, has destroyed human ingenuity interesting products, and [in fact] it is mercy without even the benefit of mankind overview. On the other hand Feyerabend considers that the emphasis on technique and rationality and its imposition on human life is the reason for killing creativity. "Advance knowledge" in many places means killing minds.... "(Feyerabend, 1996).

Feyerabend does not consider himself as anti-science and considers it as one of the most interesting inventions of the human mind and considers himself as savior and protector of culture. In fact, he explains science in his book, "Against Method" and believes that the scientific method, "is not supposed to describe what scientists are 
actually doing. Rather it is supposed to provide us with normative rules" (Oberheim and Honingen Huene, 2000).

Feyerabend has serious criticisms about education or method of education and considers it, in a way, a deception and simplification for the learner. "Of course now, simplifying the operating environment where the scientist works in by making the main component of it simple is possible. The purpose of education and scientific education- as we know it today- is exactly this. This type of education, "knowledge", is simplified by simplifying its participants" (Feyerabend, 1996). This is the kind of training that is common practice today is the training in view of Feyerabend. He believes that it prevents real understanding of the universe and its implications for learner, where we, in principles of scientific rationality from the perspective of Feyerabend, brought it as "rich presence" and rich presence is always richer than ability to pour it into a clear conceptual framework, for this reason, For this reason of universal understanding, existence and naturally the nature goes further than conceptual frameworks that we have set for it or methods in which their only way of understanding the universe we identify with. Even in Berkeley's analysis, two differences that can be extracted from Feyerabend's experiences in the concept of teaching. One, the change in training of new issues with the aim of getting people to become one from multiple nations and cultures and changes in the concept of learning. Second, training to be guided to save the rich variety of perspectives formed by teachers who facilitate their task is to choose (James, 2013).

\section{SCIENCE AND RATIONALITY BECOMING IDEOLOGICAL}

We begin this discussion by Feyerabend's saying that he believes that science comes of a real puzzle that needs explaining (Kuby, 2014).

Feyerabend maneuver quite a bit on science becoming an ideology and always speaks of its dangerous outcomes. As in an article entitled, "How to defend society against science" so begins, "In this article I'm going to defend the society and its members against all ideologies and science". Feyerabend compares science and ideology as equivalent and points to a delicate note, that science finds itself innocent from ideology, even anarchists who destroy the foundation of any method, leave science without criticism and argumentation and believe that it has to be preserved. If we refer to Habermas' words about ideology that every ideology is born from critique of ideology, science, in a way, gives itself a certain legitimacy that describes all ideology and traditions and this is when itself has transformed into ideology and will suppresses all other traditions.

One of the most notable implications of the approach of Feyerabend is that we must ask ourselves that, is living and a good life with beneficial methodology and critical analysis possible? As Feyerabend asks the question, "Is life desirable according to the rules of critical rationalism"? Feyerabend then brings up another question that "Is it possible to have science, as we have known it, and have these rules?"

Feyerabend says: "As far as I am concerned the first question is much more important than the second question. (lbid ). Feyerabend says it is true that science is an important part of our culture and is the center of interest of many philosophers, but rationalism and methodology is something of interest to philosophers and thinkers who look at the world from behind his spectacles. They have applied scientism and rationalism in their own personal life and have even turned it into a political model. But if we pay attention to human interest, and above all, to at the issue of human freedom (freedom from hunger, despair, freedom from the tyranny of centralized systems and not "free will" academic), in this case (with critical rationality) we will proceed in the worst possible way. Education field of rationalist, isn't necessary to its exact and methodical meaning, rather it is not even possible. Of course, is dependent to the overall approach to education. If we consider education as life itself, be able to give students the freedom, imposing rationality is, in a way, cruelty to students. This is inconsistent with the spirit of humanistic education and on the other hand, with student's freedom in teaching and learning in the field of creativity, and we will provide such innovations that are beyond that circle of defined critical rationality.

Based on scientific principles that Feyerabend takes into consideration for reasonableness and common criticism of rationality most important implications of methodology can be extracted for educational research.

Pluralism (plurality): Feyerabend is extremely pluralist in each of his intellectual course, means Feyerabend has been accepted in pluralism and plurality as to the meaning of developing and creating legitimate and accepted theories of incompatible theories.

Feyerabend, along pluralism, has a very broad perspective, which includes religion and religious attitudes and even myths as well (James, 2013). In his own right, James Kidd believes that in Feyerabend's view:

"Central to that pluralism is the epistemological conviction that the use of 'radical alternatives' to prevailing theories and methods enables 'immanent critique' of entrenched systems of thought and practice. The use of radical alternatives can afford new and otherwise unavailable forms of empirical and theoretical critique and so provides an essential strategy for countering 'conceptual conservatism' - roughly, a tendency for enquirers to drift into a state of unreflective reliance upon a fixed set of epistemic resources that, in turn, can lead into a state of inadvertent dogmatism. On this reading, Feyerabend argues that progressive enquiry requires active resistance to conceptually conservative tendencies through appeal to radical alternatives to currently established systems of thought and practice" 
(James, 2015)

Dyer also believes that:

"Feyerabend claims that "a scientist who is interested in maximal empirical content, and who wants to understand as many aspects of his theory as possible, will adopt a pluralistic methodology." This provides a strong and not merely tolerant claim for methodological pluralism"(Dyer, 2011).

In other words, Feyerabend's argues for freedom of society is the increasing restriction sare the increased restrictions have been lifted in culture. Again, these principles are various ways in Feyerabend's writings show, which includes a strong defense of pluralism both in science and in philosophy, prejudice and hostility towards conservatism, defense of beliefs and unusual practices such as voodoo and astrology, and the constant need to explore ideas, styles and different perspectives. Furthermore, for this reason, the Hickey says:

"Feyerabend proposed a second methodological principle, the "principle of proliferation", and he asks rhetorically, why not start proliferating theories at once, and why allows a purely normal science, as Kuhn conceives it, ever to come into existence "'"(Hickey, 2014)?

James Kidd pointed this out, in an article, in this way:

"It is clear that Feyerabend agreed that freedom must include knowledge and familiarity with developing alternatives to achieve is to understand the transferability and credibility. That subject reflects points, pluralistic epistemology and Feyerabend's sense that the student must prepare a survey of the possibilities of human existence. This survey needs to induce a rich repository of the alternatives offered by the humanities, religions ancient traditions. This helps to explain why Feyerabend argues about this subject that here are many different methods of life-in different times and different cultures-and that such diversity gradually, with abuses of the past practices and identical views in modern society will disappear. Such progressive destruction is not only simply a concern about the reduction of cultural diversity-due to modernism-but is reduction of awareness of the fact that here is alternative replacement to the dominant life and it reflects what the purpose of Feyerabend in his unfinished book "Conquest of Abundance" (James, 2013).

In Feyerabend's view, no new theory should be abandoned due to incompatibility with the theory (methods) and the famous saying, "anything is possible" is in the context of pluralism of Feyerabend. Methodological pluralism in research and educational research methodology can be widely ignored; in this regard plura- lism in a sense acts as a full mirror which defects of a dominant method is seen, meaning sometimes, in order for layers and method dimensions to become explainable, pluralism causes understanding the method a bit more. Pluralism's educational research in this direction can appear comparatively, meaning that if a subject is selected, it should be addressed comparatively and from other method's views. This view can achieve a more prominent role and place higher, particularly in the field of philosophical research in education, if such research in the field of philosophy of education is largely seen, which is that same research that is issued from the perspective of different philosophical schools or a school of philosophy in all its branches, for example, the definition of the word education in the views of idealistic, realistic, existentialism, pragmatic, postmodernism, analytic philosophy, and many more. Similarly, other issues and topics of research, with the extension of this approach to all aspects and dimensions of the subject matter will be discussed. A stability method or consistent methodology and the researcher:

It is perhaps the most important principle of the philosophy of Popper that can be put against the absolute revocation and exclusion. Because Popper denies every previous theories including Kuhn's views and believes that the purpose of gaining science is to find theories that get closer to the concept of truth with clear discussion. (Hickey, 2014) In fact, Fayrband was a Popperian because he acknowledged a philosophical principle of epistemology together with falsifications and inductive skepticism (Oberheim and Huene, 2000).

Collodel (2015) also believes that:

Feyerabend stretched Popper's views to such an extreme limit that he lost control of the consequences of his magic performance (Collodel, 2015).

Here, Geelan believes that:

"Popper's perspective is itself a step away from logical positivism: it does not assert that scientific theories are true, simply that the best available theories are those that (a) explain observations better than competing theories and have yet to be falsified." (Geeelan, 2003)

Feyerabend also says:

"Passionately advocated theoretical pluralism, which he supported by means of various Strategies" (Tambolo, 2015).

He also believes that the researcher can defend a theory, by picking it, against the revocation and denial and can expand that view and extract the best results from it.

But the researcher at the time of selecting the theory or method, must consider two things; first, select the theory or the method that yields the best results, then not to let go of the method at the first sign of trouble in said method 
and tend to changing the method. Feyerabend says, "The principle of stability is reasonable because theories can be developed, and it is reasonable because they can become better, they can find the capability to solve the same problems they were unable to solve at the beginning".

\section{A critical look at methods}

A researcher, who works with a free view and as Feyerabend says an anarchist view, will always look into the methods and even at the subject itself, with critical eye glasses. In fact, in Feyerbend's view, anarchy is a basic method in teaching. He believes:

"Anarchism is a world concept based upon a mechanical explanation of all phenomena,' writes Kropotkin. 'Its method of investigation is that of the exact natural sciences ... the method of induction and deduction.' 'It is not so clear,' writes a modem 'radical' professor at Columbia, 'that scientific research demands an absolute freedom of speech and debate. Rather the evidence suggests that certain kinds of unfreedom places no obstacle in the way of science. .."

In fact, Feyerabend's aim, rejecting criticism is the tradition and practices that surround the researcher. Even the approach of critical rationality itself, the researcher must also criticize the methodology of critical rationality and try to make change in it.

A free society is a society in which all traditions, equal rights, equal access to education, and other strong opportunities are provided. If traditions only have one advantage from the point of view of other traditions, then selecting one tradition as the foundation of a free society; is voluntary action and can only be justified resorted to force.

Feyerabend's epistemology can be called a free epistemology by expressing this sentence. Freedom for researcher is noteworthy from many dimensions; first, how much education systems provide freedom of the learners and where do they limit them. The researcher must be free to choose the subject and how to deal with it. Feyerabend in criticizing rationality-oriented approach comes to this conclusion that this type of methodology in science, is somehow imposed to the researcher and consequently, the whole system of knowledge from research on the kind of ideological rationalist and deterministic views that follows specific goals and is after removal and ignoring other traditions of human life to produce knowledge and Feyerabend's philosophy aims for service of freedom. (BakhshZadeh, 2011)

Howard Sankey(2011) in an article, by saying that proof of Feyerabend's book is mostly for "jokes", to explain and express anarchist in a free society says:

\footnotetext{
"In science in a Free Society, he said that 'anything
}

goes' was "a jocular summary of the predicament of the rationalist" who insists on universal standards" (Sankey, 2011)

Also, in an article entitled "Freedom without foundation," the author claims:

"In Feyerabend's teachings, to preserve freedom, we must be committed to a tradition. If we cannot reach an agreement with the tradition itself, freedom will jump over tradition with one leap. Certainly there are many traditions where values of freedom have found just as much limited potential and most are against advancement, in another name. Therefore, in addition to a complete theory of the social process, a very strong ethical framework is needed." (Gergen, 1986)

\section{Conclusion}

Many critiques consider Feyerabend as an "anti-science". But it's better to consider this that he is not anti-science but as anti-science of a critic, of the false concepts and exaggerated, or the nature, scope, and value of science.

In Feyerabend's view, investigator should look at the world so its grasp is much further than its limitations to one or few specific methods. Every phenomenon that appears to us always has the possibility of unknown layers within it. Feyerabend will accept scientific plausibility only in the case when researcher always considers science and the scientific method more limiting and incomplete than life itself. Feyerabend points to history in order to explain the plausibility of knowledge, from his perspective, calls it the richness. "History, in general, and especially the history of the revolution, is always richer in terms of content and variety of being alive, comprehensive and accurate, better than best historians or epistemologists can imagine."

Epistemology must generally and a researcher particularly, take this into account this point and always recognize the methodological limitations and think creatively and to benefit from the method of their liberty, as well as other members of society.

"History is full of events and guesses and the sequence of events and this proves to us that complexity of the human and non-stereotypical attributes (or unpredictable forecast) are the final results of any act or decision of the people." Do we really believe that raw and simple rules epistemologists use are capable of justifying "complexities caused by the interactions and regrets"? Is it not clear that successful participation in a flow of this kind is possible only for a bold opportunist person, who is not affiliated to any particular philosophy and will accept any practical way that provides the opportunity?

Feyerabend quotes Einstein: External conditions that empirical phenomena provide for the [scientist], do not allowed him, through adherence, to be so limited to an epistemological system that their conceptual world. 
Therefore, he must appear as reckless opportunistic before systematic epistemologists...." (lbid)

The researchers, while investigating, should not be bound to any particular method and should just chose one method with the excuse that it is rational and systematic. This approach should be considered in the field of education and the approach is doubly important to education and educational research. A successful educational system is a system that will provide its learners intellectual creativity and on the other hand researchers in the field of education deals with human beings and human phenomena and it can be said that, human beings are the most complex in all existence and hence when dealing with educational events' riddle, this one importance should always be considered.

It seems that against the modernist epistemology viewpoints and structural-oriented and its implications in the field of educational research that are emphasized in logic and logical rationality and scientific in research, considering Feyerabend's stance, since it is a Poststructuralism view in the field of science, he has introduced rationality and knowledge which has its own implications for research in education, today is the necessity of philosophical research.

\section{Conflict of Interests}

The author has not declared any conflicts of interest.

\section{REFERENCES}

Brown M (2014).“The Abundant World. Paul Feyerabend's Metaphysics of Science". Published by Elsevier.p.30.

Collodel M (2015). "Feyerabend's Theoretical Pluralism vs. Popper's Critical Rationalism Continuities and Ruptures". Institute of Philosophy, Humborg University. Berlin Germany p.2.

Dyer M (2011). "The politics of science and science of politics: Feyerabend, pluralism and democratic challenges".Paper prepared for presentation at the Annual Meeting of the Western Political Science Association, April 20-23, San Antonio, TX. DRAFT 4-9-2011. pp.1-27.

Feyerabend P (1993). "Against Method".3rd edn.(London Verso). p.228.

Feyerabend P (1996). "Against method". Translated by Ghavam Safari. Published by Roz.pp.258-368.

Gergen K (1986). "Freedom without foundation". Review of 'Science? Free Society by Paul Feyerabend. New York: Schocken Versa p.122.
Geeelan D (2003). "The Death of Theory in Educational Research". Proceedings of the 2003 Complexity Science and Educational Research Conference October 16-18 Edmonton, Canada. p.174.

Hickey T (2014). "Thomas Kuhn on revolution and Paul Feyeraband on anarchy".J. Gen. Philos. Sci .pp.20-22.

Hoyningen-Huene P (1994). "Obituary of Paul K. Feyerabend (1924-1994)[short version, 1994"].Kluwer academia publisher p.291.

Hoyningen-Huene P (2000)."Paul K. Feyerabend: An Obituary [long version, 2000]. New York Oxford University Press p.11.

Iman M (1997)."Take a look at the principles of the methodology of scientific research".Published by Philoso. Res. J. 165(1):60-73

James KI (2013).“Feyerabend on Science and Education”.J. Philos. Educ. 47(3):5.

James KI (2013)."Feyerabend on Politics Education and Scientific Culture". Stud. Hist. Philos. Sci. Phil p.412.

James KI (2015)." What's so great about Feyerabend? Against Method, forty years".Springer Science.p. 5

James KI (2013). What's so great about Science?'Feyerabend on Science. Ideology and the Cold War.Department of Philosophy. Durham University Peress p.418.

James KI (2015)."Why did Feyerabend defend astrology? Integrity, virtue, and the authority of science".Soc. Epistemology forthcoming.p.5.

Kuby D (2014)."Review of Paul Feyerabend, the Tyranny of Science". Edited by Eric Oberheim .Cambridge Polity Press p.371.

Oberheim E, Hoyningen-Huene P (2000)."Essay revies Feyrabend's early philosophy".Published by Elsevier science.p 372.

Sankey H (2011)."Essay review philosophical fairytales from Feyerabend".PaulFeyerabendthe Tyranny of Science. Edited and with an introduction by Eric Oberheim. Cambridge UK \& Malden MA: Polity Press.p 8.

ShabaniWaraki B (2007). "Critical of the methodology in education in Iran".J. Educ. 85:16-18.

Tambolo $L$ (2015)."A tale of three theories: Feyerabend and Popper on progress and the aim of science".Studies in Hist. Philos. Sci. Part A, $52: 36$.

Zarghami S (2011)."Philosophy of education research".J. Educ.Res. $1(1): 80$. 